\title{
RESULTADOS POR ACÇÃO: UMA REFLEXÃO SOBRE O NUMERADOR
}

\begin{abstract}
Catarina Xavier Amaral*
Neste artigo dedicamos a nossa atenção à temática dos resultados por acção, a qual tem merecido atenção especial por parte de diversas entidades normalizadoras, dada a sua apetência para aferir o progresso e o desempenho de uma entidade. A International Accounting Standard (IAS) $n .^{\circ} 33$, Earnings per Share e o Statement of Financial Accounting Standards (SFAS) $n .^{\circ} 128$, com a mesma designação, são o resultado de 3 anos de esforços e de cooperação entre o International Accounting Standards Committee (IASC) e o Financial Accounting Standards Board (FASB), com o objectivo de clarificar o cálculo do resultado por acção, enunciando princípios para a sua determinação $e$ apresentação que permitam melhorar as comparações à escala global.

Depois de devidamente clarificados os objectivos, alcance e âmbito de aplicação dos resultados por acção, a nossa análise centra-se na determinação deste indicador, com especial destaque para os resultados (numerador), os quais são abordados à luz dos conceitos constantes da Directriz Contabilística (DC) n. ${ }^{\circ} 20$ - Demonstração dos Resultados por Funções.

Deixaremos o estudo do denominador da fórmula de cálculo do resultado por acção para posterior desenvolvimento.
\end{abstract}

Palavras-chave: resultado por acção, demonstração dos resultados, proveitos, custos, ganhos e perdas.

\footnotetext{
" Departamento de Economia, Gestão e Ciências Sociais do Centro Regional das Beiras da Universidade Católica Portuguesa.
} 


\section{1 - PERSPECTIVA HISTÓRICA}

Em resultado do crescendo de complexidade do relato financeiro, por sua vez consequência das cada vez mais complexas transacções comerciais e formas de estruturar os negócios, os utentes das Demonstrações Financeiras desde sempre procuraram um meio simples e conciso de aferir o progresso e a performance de uma empresa.

O resultado por acção é um rácio frequentemente utilizado pelos investidores, actuais e potenciais, e outros interessados, na avaliação da rendibilidade das empresas. O resultado por acção indica o lucro (prejuízo) atribuído a cada acção ordinária. A função deste indicador é evidenciar, de uma forma simples e facilmente comparável, a eficiência da empresa na utilização dos recursos postos à disposição pelos seus accionistas.

Durante anos, a profissão contabilística desencorajou a utilização do resultado por acção ou de outro qualquer indicador condensado de avaliação da performance da empresa, na medida em que omitia muita da informação detalhada proporcionada pelas Demonstrações Financeiras e tida como essencial para compreender, verdadeiramente, as operações da empresa. Contudo, quando a procura de um indicador deste tipo se tornou irresistível, os contabilistas procuraram desenvolver conceitos que, no mínimo, assegurassem que qualquer medida deste tipo fosse aplicada de uma forma válida e consistente. Assim, a profissão reconheceu que calcular o resultado por acção, ignorando todos os potenciais valores mobiliários' que poderão ter um efeito de diluição no resultado por acção, tornava-o enganador, além de que, a falta de normalização sobre a forma de fazer incluir estes valores mobiliários no cálculo do resultado por acção, tornava as comparações, entre empresas, extremamente difíceis.

Por estas razões, vários organismos normalizadores têm tentado, nos últimos 40 anos, estabelecer a fórmula de cálculo do resultado por acção. A primeira tentativa levada a cabo pela profissão, no sentido de normalizar o cálculo do resultado por acção, foi feita em 1958 através do Accounting Research Bulletin $\mathrm{n}^{\circ}{ }^{\circ}$ 49. Contudo, esta norma foi simplesmente ignorada e todas as empresas continuaram a calcular o resultado por acção dividindo os resultados líquidos do período, deduzidos dos dividendos correspondentes às acções preferenciais, pelo número médio ponderado de acções ordinárias em circulação durante $o$ período.

No entanto, a distorção existente no cálculo tradicional do resultado por acção tornou-se evidente com a vaga de fusões e aquisições dos anos 60. Uma das consequências destes processos de fusões e aquisições foi, sem dúvida, o aumento na utilização de outros valores mobiliários tais 
como, obrigações convertíveis ${ }^{2}$, acções preferenciais convertíveis ${ }^{3}$, warrants $^{4}$ e emissões contingenciais de acções ${ }^{5}$, como forma de estruturar o negócio. Apesar de na forma não serem acções ordinárias, estes instrumentos financeiros permitem aos seus titulares, através do seu exercício ou conversão, a obtenção de acções ordinárias.

Muitas destas fusões, que se traduziram num relato de resultados mais elevado para a entidade combinada, foram levadas a cabo através da emissão de valores mobiliários convertíveis, opções e warrants e pela eliminação das acções ordinárias da empresa fundida. Desta forma, uma empresa que não tomasse em consideração o número destes valores mobiliários dilutivos ${ }^{6}$ em circulação, no cálculo do resultado por acção, evidenciaria um aumento do indicador sem o correspondente aumento de rendibilidade, uma vez que a empresa apresentaria um resultado combinado maior dividido por um número menor de acções ordinárias.

Assim, a Accounting Principles Board (APB) - Opinion n. ${ }^{\circ}$, , de 1966, aconselhava as empresas com potenciais valores mobiliários dilutivos em circulação (aç̧ões preferenciais convertíveis, obrigações convertíveis ou com opções e warrants), materialmente relevantes, a calcular um resultado por acção suplementar, evidenciando quais seriam os resultados atribuídos a cada acção ordinária se ocorressem conversões ou emissões contingenciais.

A APB - Opinion n. ${ }^{\circ}$ 15, emitida em 1969 pelo American Institute of Certified Public Accountants (AICPA), definia com mais precisão os valores mobiliários com potencial para diluir o resultado por acção, proporcionava um guia mais detalhado em matéria de cálculo e delineava os requisitos de relato e divulgação. Todavia, a APB - Opinion $\mathrm{n}^{\circ} 15$ foi amplamente criticada pela sua complexidade e arbitrariedade na forma de tratar os valores mobiliários potencialmente dilutíveis.

Na sequência destas críticas, o Financial Accounting Standards Board (FASB) encetou, em meados de 1993, um processo de procura de soluções para substituir a APB - Opinion n. ${ }^{\circ} 15$ e as suas 102 interpretações. Uma vez que o resultado por acção é um dos indicadores financeiros mais amplamente utilizados, o International Accounting Standards Committee (IASC), que até então nunca fizera incluir em nenhuma norma internacional de contabilidade as regras de cálculo do resultado por acção, sentiu necessidade de desenvolver uma posição oficial nesta matéria, iniciando uma abordagem conjunta com o FASB, com vista à determinação e apresentação de um resultado por acção que permitisse comparações à escala global.

O esforço conjunto levado a cabo pelos organismos de normalização americano (FASB) e internacional (IASC), na procura de uma harmonização internacional para as normas contabilísticas do cálculo do resultado por acção, culminou com a emissão, em Fevereiro de 1997, do 
Statement of Financial Accounting Standards (SFAS) n. ${ }^{\circ} 128$ - Earnings per Share, pelo FASB e do International Accounting Standard (IAS) n. ${ }^{\circ}$ 33 - Earnings per Share, pelo IASC, com conteúdos, substancialmente, idênticos. Esta nova abordagem para o cálculo e apresentação dos resultados por acção é também consistente com os requisitos em vigor em outros países, nomeadamente no Reino Unido com a publicação, em Outubro de 1998, do Financial Reporting Standard (FRS) n..$^{\circ}$ 14, Earnings per Share, pelo Accounting Standards Board (ASB).

\section{2 - OBJECTIVOS E ALCANCE DO RESULTADO POR ACÇÃO}

A temática dos resultados por acção não interessa somente aos accionistas (shareholders) actuais ou futuros, em particular, mas também a todos os interessados em avaliar o desempenho e a situação da empresa (stakeholders), em geral. Ninguém dúvida que os resultados apresentados pelas empresas são um indicador importante para os agentes económicos, com particular destaque para os investidores. Todavia, aqueles devem ser medidos na proporção das acções correspondentes. Por esta razão, o relato do resultado por acção é necessário na medida em que reduz o resultado à dimensão do capital que o produziu. De facto, afirmar que o resultado foi de $\mathrm{X}$ ou $\mathrm{Y}$, ou de que é muito ou pouco elevado, poderá ser enganoso, porque tal resultado tem de ser analisado em função do capital aplicado. Assim, o relacionamento dos resultados com uma única acção auxilia os investidores a procederem a comparações de desempenho e de lucratividade relativa, entre empresas.

Podemos, então, concluir que a importância do resultado por acção se deve, essencialmente, ao facto de permitir comparar a rentabilidade de empresas com estruturas e dimensões diferentes, para além de que facilita a análise dos resultados e do desempenho da empresa em termos temporais. Com efeito, mesmo que os resultados totais cresçam, a diminuição dos lucros por acção poderá indiciar sintomas menos favoráveis para a empresa.

Neste contexto, compreendem-se os esforços de normalização realizados por vários organismos de contabilidade, no sentido de melhorar a determinação, apresentação e divulgação dos resultados por acção. O parágrafo . $^{\circ} 1$, do SFAS n. $^{\circ} 128$, reforça esta ideia, ao referir que um dos objectivos da norma é o de tornar o cálculo dos resultados por acção, segundo as normas aplicáveis nos EUA, mais compatível com o de outros países, e com as normas do IASC, compreendendo-se, assim, as várias semelhanças entre as duas normas. 
O objectivo principal inerente à publicação destas normas foi o de enunciar princípios para a determinação e apresentação dos resultados por acção, que permitam melhorar as comparações de desempenho entre diferentes empresas para o mesmo período e entre períodos contabilísticos diferentes, para a mesma entidade.

Tanto a norma do IASC como a do FASB dão toda a ênfase ao cálculo do denominador do resultado por acção e fazem notar que apesar do cálculo do resultado por acção ter limitações, devido às diferentes políticas contabilísticas que podem ser utilizadas para apuramento dos resultados, i.e., o numerador do resultado por acção, um denominador determinado de forma consistente melhora o relato financeiro.

No que concerne ao âmbito de aplicação das normas, ambas referem que estas se aplicam quer a empresas com acções ordinárias ${ }^{7}$ ou com potenciais acções ordinárias ${ }^{8}$ transaccionadas publicamente, quer a empresas que estão em processo de emitirem acções ordinárias ou potenciais acções ordinárias em Mercado de Valores Mobiliários ${ }^{9}$. Portanto, a excepção refere-se às empresas cujas acções não são negociadas publicamente. No entanto, uma entidade que não tenha quaisquer acções ordinárias nem potenciais acções ordinárias a serem transaccionadas numa bolsa de valores, mas que divulga resultados por acção, deverá calcular e divulgar esses resultados por acção em conformidade com a IAS n. ${ }^{\circ} 33$.

Refira-se, ainda, que quando são apresentadas, simultaneamente, as Demonstrações Financeiras consolidadas e as da empresa mãe, a informação a que a IAS n. ${ }^{\circ} 33$ obriga, apenas precisa de ser dada com base, única e exclusivamente, nas Demonstrações Financeiras consolidadas. Isto porque, segundo o parágrafo n..$^{\circ} 3$ da IAS n..$^{\circ} 33$, os utentes das Demonstrações Financeiras da empresa mãe estão, normalmente, preocupados com, e necessitam de estar informados sobre, os resultados das operações do grupo como um todo.

$\mathrm{Na}$ sua forma mais simples, o resultado por acção é calculado dividindo o resultado líquido do período pelo número médio ponderado de acções ordinárias em circulação durante o período. $\mathrm{O}$ objectivo em calcular o resultado por acção consiste em determinar o montante do resultado atribuído a cada acção ordinária. As complexidades surgem porque o resultado líquido não representa, necessariamente, os resultados disponíveis para os accionistas ordinários, e uma simples média ponderada das acções em circulação também não reflecte, necessariamente, a verdadeira natureza da situação. Os ajustamentos assumem a forma de manipulações no numerador e no denominador da fórmula usada para calcular o resultado por acção.

As empresas são obrigadas a divulgar o valor do resultado por acção básico $^{10} \mathrm{e}$ diluído ${ }^{11}$ na face da demonstração dos resultados, com respeito 
a cada classe de acções ordinárias que tenham direitos diferentes de participar no lucro ou prejuízo do período. Os numeradores dos cálculos apresentados devem ser divulgados e reconciliados com o lucro ou prejuízo líquido para o período. Os denominadores utilizados no cálculo do resultado por acção básico e diluído devem, também, ser divulgados e reconciliados um com o outro.

O resultado por acção básico é visto, pela norma, como uma medida da performance passada da empresa, calculado dividindo o lucro (prejuízo) atribuído aos accionistas ordinários pelo número médio ponderado de aç̧ões ordinárias em circulação durante o período.

A IAS n. ${ }^{\circ} 33$ prescreve os métodos através dos quais o número médio ponderado de acções ordinárias em circulação deverá ser ajustado com respeito a eventos que, sem que haja uma correspondente modificação nos recursos financeiros da empresa, alterem o número de acções ordinárias em circulação. Tais eventos incluem o split de acções ${ }^{12}$, a atribuição de dividendos na forma de acções e o reverse share split ${ }^{13}$. Sempre que estes acontecimentos ocorram depois da data de balanço mas antes da data de aprovação das Demonstrações Financeiras, todas as quantias por acção apresentadas devem basear-se no número de acções em circulação depois da ocorrência de tais acontecimentos.

O resultado por acção diluído é, também, apresentado como uma medida da performance passada da empresa mas que inclui o efeito de potenciais acções ordinárias em circulação durante o período. As únicas potenciais acções ordinárias a serem incluídas no cálculo do resultado por acção diluído são apenas aquelas que tiverem um efeito dilutivo, i.e., aquelas que, mediante conversão em acções ordinárias, irão diminuir o lucro líquido por acção ou aumentar o prejuízo líquido por aç̧ão das operações continuadas. A IAS n. 33 fixa a sequência pela qual as potenciais acções ordinárias dilutivas devem ser consideradas na determinação do número médio ponderado de acções, para cálculo do resultado por acção diluído.

\section{3-O NUMERADOR}

O resultado disponível para os accionistas ordinários, utilizado como numerador em qualquer cálculo do resultado por acção, deve estar deduzido de quaisquer direitos preferenciais sobre ele. Esta redução justifica-se porque os direitos preferenciais de outras acções devem ser 
satisfeitos antes do resultado se tornar disponível para o accionista comum.

Estas outras acções assumem a forma de acções preferenciais ${ }^{14}$ e o montante a deduzir ao resultado corresponde ao montante dos dividendos declarados, independentemente de estarem ou não pagos, durante o ano, para as acções preferenciais.

$\mathrm{Se}$ as acções preferenciais forem acumulativas, o dividendo é deduzido ao lucro (ou adicionado ao prejuízo), independentemente de ser ou não declarado. Assim, estes dividendos em atraso, quer declarados ou não, não afectam o cálculo do resultado por acção do período uma vez que tais dividendos já foram considerados no cálculo do resultado por acção de períodos anteriores. Contudo, o montante de dividendos em atraso deverá ser divulgado, bem como todos os efeitos dos direitos atribuídos às acções preferenciais, no cálculo do resultado por acção.

$\mathrm{Se}$ as acções preferenciais não tiverem um direito acumulativo sobre os dividendos, e se os dividendos do período tiverem sido omitidos, tais dividendos não deverão ser deduzidos no cálculo do resultado por acção.

\section{1 - Que resultado?}

O resultado utilizado no cálculo do resultado por acção será o apurado na Demonstração dos Resultados a que se refere a IAS n. ${ }^{\circ} 1$ Presentation of Financial Statements, bem como a nossa Directriz Contabilística (DC) n. ${ }^{\circ} 20$, cuja elaboração passou a ser de carácter obrigatório com a publicação do Decreto-Lei n. ${ }^{\circ} 44 / 99$, de 12 de Fevereiro. No seu artigo $3 .^{\circ}, \mathrm{n} .^{\circ} 2$, pode ler-se: "A demonstração dos resultados por funções ... é de elaboração obrigatória para as entidades referidas no $n .^{\circ} 1$ do artigo $2 .^{\circ}$ do Decreto-Lei $n .^{\circ} 410 / 89$, de 21 de Novembro, que tenham ultrapassado dois dos três limites referidos no artigo $262 .^{\circ}$ do Código das Sociedades Comerciais ${ }^{15}$, a partir do exercício seguinte ao da respectiva ocorrência." No n. ${ }^{\circ} 3$ do anexo do mesmo Decreto-Lei refere-se que: “... O modelo e os conceitos adoptados são os constantes da Directriz Contabilística n..$^{\circ} 20$, «Demonstração dos resultados por funções»»..."

A Demonstração dos Resultados tornou-se, sem dúvida, na Demonstração Financeira mais importante para os investidores. A Demonstração dos Resultados ajuda os utilizadores, nomeadamente, os investidores a avaliar o desempenho conseguido pela empresa, em particular a sua rendibilidade, com vista a determinar as alterações potenciais nos recursos económicos que seja provável que a empresa controle no futuro. Esta informação acerca do desempenho revela grande utilidade, pois permite prever a capacidade da empresa em gerar fluxos de 
caixa a partir dos recursos actuais e formar juízos quanto à eficiência com que a empresa pode afectar recursos adicionais.

Esta Demonstração Financeira, conjuntamente com a Demonstração das Variações do Capital Próprio, instituída pelo IASC, na IAS n. ${ }^{\circ}$, asseguram informação adequada sobre a variação do património durante o período e sobre a totalidade dos ganhos e das perdas geradas pela globalidade das actividades da empresa.

Fazem parte da Demonstração dos Resultados os seguintes elementos:

1. Proveitos, "são os aumentos nos benefícios económicos durante o período contabilístico na forma de influxos ou de melhorias de $\operatorname{activos}^{16}$ ou de diminuições de passivos ${ }^{17}$ que resultem em aumentos no Capital Próprio ${ }^{18}$, que não sejam os relacionados com as contribuições dos participantes no Capital Próprio" "19;

2. Custos, "são as diminuições nos benefícios económicos durante o período contabilístico na forma de exfluxos ou deperecimentos de activos ou na incorrência de passivos que resultem em diminuições no Capital Próprio, que não sejam as relacionadas com as distribuições aos participantes no Capital Próprio",20;

3. Ganhos, "representam itens que satisfazem a definição de proveitos e que podem ou não surgir no decurso das actividades correntes (ordinárias) de uma entidade. Os ganhos representam aumentos nos benefícios económicos e, como tal, não têm uma natureza diferente dos proveitos, pelo que a estrutura conceptual do IASC não os considera isoladamente",21;

4. Perdas, "representam itens que satisfazem a definição de custos e que podem ou não surgir no decurso das actividades correntes (ordinárias) de uma entidade. As perdas representam diminuições nos benefícios económicos e, como tal, não têm uma natureza diferente dos custos, pelo que a estrutura conceptual do IASC não os considera isoladamente",22;

Com base nas definições apresentadas, podemos concluir que o IASC, na sua estrutura conceptual, contemplou uma definição ampla de proveitos e custos por forma a abranger quer os ganhos quer as perdas. Os proveitos, definidos como resultantes das actividades correntes (ordinárias) da empresa, podem assumir muitas formas, tais como, vendas, prestações de serviços, honorários, juros, dividendos, royalties e rendas. São exemplos de custos, o custo das vendas, as amortizações, os juros pagos, as rendas pagas, os ordenados e salários e os impostos, e 
caracterizam-se por darem origem a um fluxo de saída de caixa ou a um deperecimento de outros activos.

Os ganhos (perdas) representam, também, aumentos (diminuições) nos benefícios económicos e a sua natureza é semelhante à dos proveitos (custos). Contudo, existe uma ténue diferença entre os dois conceitos: os ganhos (perdas) podem ou não surgir no decurso das actividades correntes (ordinárias) de uma entidade, enquanto que os proveitos (custos) resultam das actividades correntes. Consequentemente, uma perda resultante de um item extraordinário como seja um desastre natural está incluída nesta definição.

Os ganhos e as perdas são, então, caracterizados pelo facto de resultarem de transacções periféricas e de circunstâncias que poderão estar fora do controlo da empresa, e poderão ser classificados como operacionais ou não operacionais.

Os ganhos e perdas são de vária natureza, podendo resultar da venda de investimentos, de instalações, extinção de passivos, abates de activos e desastres como sejam os incêndios e as inundações.

Refira-se, ainda, que a definição de ganhos e perdas também contempla os ganhos e perdas não realizados, como por exemplo, os ganhos resultantes dos aumentos no valor contabilístico dos activos de longo prazo e as perdas resultantes dos efeitos dos aumentos ou diminuições na taxa de câmbio de uma divisa relativamente a dívidas a e de terceiros, expressas nessa divisa.

Quando os ganhos e as perdas são reconhecidos na Demonstração dos Resultados, a sua divulgação é, normalmente, feita em separado, na medida em que o seu conhecimento é útil para a tomada de decisões económicas fundamentadas, para além de serem relatados líquidos dos custos e dos proveitos relacionados.

De facto, o relato destes diferentes elementos não deve ser subestimado. Para muitos decisores, os diferentes componentes das Demonstrações Financeiras são mais importantes e de maior utilidade que o conjunto final. Os investidores e os credores estão interessados em perspectivar os montantes, os momentos e a incerteza dos fluxos financeiros, e se a Demonstração dos Resultados lhes proporcionar os seus diferentes elementos com algum detalhe, bem como a comparação com anos anteriores, eles estarão, sem dúvida, melhor apetrechados para poderem estimar resultados e fluxos de caixa futuros.

Sendo assim, a Demonstração dos Resultados apresenta a seguinte estrutura: 


\begin{tabular}{|c|c|c|}
\hline & \multicolumn{2}{|c|}{ EXERCÍCIOS } \\
\hline & $\mathbf{N}$ & $\mathrm{N}-1$ \\
\hline Vendas e prestações de serviços & $\mathrm{X}$ & $\mathrm{X}$ \\
\hline \multirow{2}{*}{$\begin{array}{l}\text { Custo das vendas e das prestações de serviços } \\
\text { Resultados brutos }\end{array}$} & $-X$ & $-X$ \\
\hline & $+/-X$ & $+/-\mathrm{X}$ \\
\hline Outros proveitos e ganhos operacionais & $\mathrm{X}$ & $\mathrm{X}$ \\
\hline Custos de distribuição & $-X$ & $-\mathrm{X}$ \\
\hline Custos administrativos & $-\mathrm{X}$ & $-\mathrm{X}$ \\
\hline \multirow{2}{*}{$\begin{array}{l}\text { Outros custos e perdas operacionais } \\
\text { Resultados operacionais }\end{array}$} & $-X$ & $-\mathrm{X}$ \\
\hline & $+/-X$ & $+/-X$ \\
\hline \multirow{4}{*}{$\begin{array}{l}\text { Custo líquido de financiamento } \\
\text { Ganhos (perdas) em filiais e associadas } \\
\text { Ganhos (perdas) em outros investimentos } \\
\text { Resultados correntes antes de impostos }\end{array}$} & $+/-X$ & $+/-X$ \\
\hline & $+/-X$ & $+/-X$ \\
\hline & $+/-X$ & $+/-X$ \\
\hline & $+/-X$ & $+/-X$ \\
\hline \multirow{2}{*}{$\begin{array}{l}\text { Impostos sobre os resultados correntes } \\
\text { Resultados correntes após impostos }\end{array}$} & $-\mathrm{X}$ & $-\mathrm{X}$ \\
\hline & $+/-X$ & $+/-X$ \\
\hline \multirow{3}{*}{$\begin{array}{l}\text { Resultados extraordinários } \\
\text { Impostos sobre os resultados extraordinários } \\
\text { Resultados líquidos }\end{array}$} & $+/-X$ & $+/-X$ \\
\hline & $-X$ & $-X$ \\
\hline & $+/-X$ & $+/-X$ \\
\hline Resultados por acção & $+/-X$ & $+/-\mathrm{X}$ \\
\hline
\end{tabular}

Fonte: Directriz Contabilística n. ${ }^{\circ} 20$

No formato apresentado, e constante da Directriz Contabilística $n .^{\circ} 20$, é possível evidenciar uma seç̧ão composta pelas actividades ordinárias da empresa onde são relatados os proveitos e os custos das actividades principais da empresa e que incluem:

4 Vendas e prestações de serviços que "respeita ao rédito proveniente das vendas e das prestações de serviços, líquido dos descontos e dos impostos inerentes";

$\Leftrightarrow$ Custo das vendas e das prestações de serviços que "corresponde ao custo dos bens e dos serviços vendidos pela empresa";

4 Outros proveitos e ganhos operacionais que "integra os restantes proveitos e ganhos operacionais"23;

$\rightarrow$ Custos de distribuição que "são os custos associados à função venda de bens e serviços";

$\forall$ Custos administrativos que "são os custos associados à função administrativa" da empresa; 
4 $\rightarrow$ Outros custos e perdas operacionais que integra "os custos e perdas operacionais que não estiverem incluídos em qualquer das rubricas anteriores";

4) Custo líquido de financiamento que representa o custo do "financiamento contraído pela empresa, deduzido de eventuais proveitos financeiros anteriores à sua utilização"24;

$\rightarrow$ Ganhos (perdas) em filiais e associadas que corresponde ao resultado obtido do balanceamento entre as contas "Ganhos em empresas do grupo e associadas" e "Perdas em empresas do grupo e associadas", aí incluindo o resultado derivado da aplicação do método da equivalência patrimonial, como decorre da IAS n. ${ }^{\circ} 1-$ Apresentação das Demonstrações Financeiras. Deverá, também, ser englobado nesta linha o resultado da alienação do investimento;

(4) Ganhos (perdas) em outros investimentos, incluindo-se sob esta rubrica o resultado do balanceamento dos saldos das contas "Rendimentos de imóveis", "Rendimentos de participações de capital" e "Amortizações de investimentos em imóveis". É ainda de incluir o resultado da alienação do investimento.

Nesta secção é feito o apuramento do imposto, apresentando-se o resultado das operações ordinárias (correntes) da empresa, líquido de imposto.

Ainda de acordo com a Directriz Contabilística n. $^{\circ} 20$, os resultados extraordinários "correspondem aos ganhos e perdas que sejam materialmente relevantes ${ }^{25}$ e cumulativamente não usuais por natureza e de ocorrência não frequente", tais como, "ganhos ou perdas resultantes de catástrofes naturais, de convulsões políticas, de expropriações ou de proibições impostas por nova legislação", bem como "os resultados materialmente relevantes derivados da extinção de passivos".

A IAS n. ${ }^{\circ} 8$ - Resultados Líquidos do Período, Erros Fundamentais e Alterações nas Políticas Contabilísticas, estabelece no seu parágrafo $n .^{\circ} 6$ que "rubricas extraordinárias são proveitos ou gastos que provêm de acontecimentos ou transacções que sejam claramente distintas das actividades ordinárias da empresa e, por isso, não se espera que sejam frequentes ou regularmente recorrentes". A esta dupla condição, a directriz da Comissão de Normalização Contabilística (CNC) veio, na linha dos US GAAP, impor a condição de materialidade.

Temos, então, que integram os resultados extraordinários os ganhos e perdas que, cumulativamente, sejam:

$\checkmark$ Quanto à sua natureza: não usuais;

$\checkmark$ Quanto ao grau de ocorrência: não frequentes;

$\checkmark$ Quanto à sua extensão: materiais.

De tudo isto resulta que sob o título "resultados extraordinários" passam, pois, a incluir-se aqueles componentes do resultado que 
envolvem um grau de anormalidade muito elevado e são de tal magnitude que a sua divulgação separada é uma exigência face ao objectivo da imagem fidedigna.

Em relação ao relato de situações especiais como sejam, por exemplo, os réditos e os gastos das actividades ou divisões em processo de descontinuação, os ganhos e perdas das actividades ou divisões já descontinuadas, os ganhos e perdas não usuais ou não frequentes e os efeitos de alterações nas políticas contabilísticas, devem, também, ser relatados na Demonstração dos Resultados.

O conceito chave é o de que qualquer ganho obtido e perda incorrida, directa ou indirectamente relacionada com a actividade normal da empresa, contribui para a sua rendibilidade a longo prazo. Como tal, os ganhos e perdas irregulares podem aparecer separados dos resultados das operações correntes da empresa e apurar-se o resultado de cada tipo de operações, mas o resultado líquido do ano deverá incluir todo o tipo de transacções. Quando é dada liberdade de tratamento e determinação destes itens irregulares, corre-se o risco de haver manipulações da informação financeira. Geralmente, as empresas utilizam esta flexibilidade em seu proveito, fugindo à Demonstração dos Resultados no caso de perdas, com a sua entrada directa no Capital Próprio e fazendo passar os ganhos irregulares pela Demonstração dos Resultados, pondo, desta forma, em causa a qualidade dos mesmos.

A solução encontrada passa pela divulgação de todos os itens irregulares na Demonstração dos Resultados, por forma a permitir que os utentes das Demonstrações Financeiras melhor possam determinar a capacidade da empresa em gerar resultados no longo prazo.

Assim, "os resultados não usuais por natureza ou de ocorrência não frequente, mas não satisfazendo simultaneamente ambas as condições, quando materialmente relevantes, são de considerar em linha separada a seguir a "Ganhos (perdas) em outros investimentos". São exemplos destes resultados: quebras anormais em existências, perdas em dividas a receber, ganhos em dívidas a pagar, flutuações cambiais e ganhos e perdas derivados da alienação de imobilizações" (cf. DC n. ${ }^{\circ} 20$ ).

Estamos aqui em presença de dois conceitos (resultados não usuais e resultados não frequentes) derivados do conceito de resultados extraordinários, já referido. De acordo com a definição qualquer ganho ou perda para ser incluído nesta rubrica deve ser material. Para que um evento ou transacção seja considerada não usual deve possuir um alto grau de anormalidade e ser de um tipo claramente não relacionado, ou apenas acidentalmente relacionado, com as actividades ordinárias e típicas da entidade, tendo em conta o meio ambiente em que esta opera. $E$. para se considerar de ocorrência não frequente, o evento ou transacção deve ser de um tipo cuja repetição não seja razoavelmente esperada num 
futuro previsível, tendo também em conta o meio em que a empresa opera. Portanto, caso se qualifiquem de materiais, mas verificando-se somente uma das restantes características, os elementos devem ser considerados numa categoria específica a incluir ainda nos resultados correntes.

Como já foi referido, os elementos extraordinários são somente aqueles acontecimentos ou transaç̧ões que tenham, conjuntamente, natureza não usual e ocorrência não frequente. Os elementos não materiais que reunam uma ou as duas características, não têm posicionamento específico, sendo combinados com outros elementos na Demonstração dos Resultados. Conclui-se, pelo exposto, que só a raridade e materialidade conferem, claramente, a qualificação de extraordinário a um acontecimento ou transacção.

No que diz respeito aos resultados de operações em descontinuação, estes devem ser apresentados líquidos de imposto, em linha separada, imediatamente antes de resultados extraordinários. A atenção dada pelos profissionais da contabilidade, a nível internacional, às operações em descontinuação deve-se ao facto de estas serem cada vez mais frequentes. A instabilidade do meio envolvente e a necessidade de competitividade têm levado, nos últimos anos, a processos de reestruturação profunda em muitas das grandes empresas, com estratégias que passam, nomeadamente, pela saída de segmentos de negócios. A continuidade da empresa é um dos grandes pressupostos da preparação das Demonstrações Financeiras. Se existir intenção ou necessidade de liquidar ou reduzir drasticamente o nível das suas operações, as Demonstrações Financeiras devem ser preparadas em regime diferente.

O IASC define operação em descontinuação ${ }^{26}$ como uma componente de uma empresa que, seguindo um plano global, esta está a alienar substancialmente ou a liquidar por abandono ou pela venda dos activos e regularização dos passivos, individualmente, que representa uma linha de negócios, uma área geográfica de operações ou uma classe de clientes e que pode ser autonomizada operacionalmente e para efeitos de relato financeiro. Com a aprovação do plano de descontinuação pela Administração e a sua divulgação pública, a empresa deve passar a divulgar nas notas às Demonstrações Financeiras, diversas informações iniciais sobre a descontinuação planeada. Logo que ocorram aç̧ões da Administração que, definitivamente, tornem a empresa comprometida com a descontinuação, a totalidade dos activos e passivos, dos fluxos de caixa e dos proveitos e ganhos e custos e perdas das operações em descontinuação devem passar a surgir, nas Demonstrações Financeiras, separados dos elementos similares relativos às operações em continuidade. 
Finalmente, os efeitos das alterações nas políticas contabilísticas devem aparecer, líquidos de imposto, em linha separada, imediatamente antes do resultado líquido.

Uma empresa, onde ocorram todas estas situações especiais, deverá apresentar uma Demonstração dos Resultados com o seguinte formato:

\section{QUADRO 2 - DEMONSTRAÇÃO DOS RESULTADOS POR FUNÇÕES} (COMPLETA)

\begin{tabular}{|c|c|c|}
\hline & \multicolumn{2}{|c|}{ EXERCÍCIOS } \\
\hline & $\mathbf{N}$ & N-1 \\
\hline Vendas e prestações de serviços & $\mathrm{X}$ & $\mathrm{X}$ \\
\hline Custo das vendas e das prestações de serviços & $-\mathrm{X}$ & $-\mathrm{X}$ \\
\hline Resultados brutos & $+/-\mathrm{X}$ & $+/-X$ \\
\hline Outros proveitos e ganhos operacionais & $\mathrm{X}$ & $\mathrm{X}$ \\
\hline Custos de distribuição & $-X$ & $-\mathrm{X}$ \\
\hline Custos administrativos & $-\mathrm{X}$ & $-X$ \\
\hline Outros custos e perdas operacionais & $-\mathrm{X}$ & $-\mathrm{X}$ \\
\hline Resultados operacionais & $+/-X$ & $+/-X$ \\
\hline Custo líquido de financiamento & $+/-X$ & $+/-X$ \\
\hline Ganhos (perdas) em filiais e associadas & $+/-X$ & $+/-X$ \\
\hline Ganhos (perdas) em outros investimentos & $+/-X$ & $+/-X$ \\
\hline Resultados não usuais ou não frequentes & $+/-X$ & $+/-\mathrm{X}$ \\
\hline Resultados correntes antes de impostos & $+/-X$ & $+/-X$ \\
\hline Impostos sobre os resultados correntes & $-\mathrm{X}$ & $-\mathrm{X}$ \\
\hline Resultados correntes após impostos & $+/-X$ & $+/-\mathrm{X}$ \\
\hline $\begin{array}{l}\text { Resultados de operações em descontinuação } \\
\text { (líquidos de imposto) }\end{array}$ & $+/-X$ & $+/-X$ \\
\hline $\begin{array}{l}\text { Resultados extraordinários (líquidos de } \\
\text { imposto) }\end{array}$ & $+/-X$ & $+/-X$ \\
\hline $\begin{array}{l}\text { Efeitos de alterações nas políticas contabilísticas } \\
\text { (líquidos de imposto) }\end{array}$ & $+/-X$ & $+/-X$ \\
\hline Resultados líquidos & $+/-X$ & $+/-X$ \\
\hline Resultados por acção & $+/-X$ & $+/-X$ \\
\hline
\end{tabular}

Refira-se, ainda, que esta Demonstração dos Resultados leva à afectação do imposto sobre o rendimento a vários estádios intermédios de resultados: . resultados correntes, resultados de operações em descontinuação, resultados extraordinários e alterações de políticas contabilísticas.

Este procedimento de afectação permite, nomeadamente, o apuramento do resultado corrente após a parcela de imposto que lhe respeita. Esta categoria de resultado é preciosa para avaliar o desempenho 
da empresa na perspectiva das suas actividades normais, cumprindo, assim, a função de orientar os utilizadores da informação financeira na tomada das suas decisões.

A Demonstração dos Resultados termina com a apresentação do rácio resultados por acção, de extrema relevância para o investidor comum, tendo em conta a informação que fornece para a avaliação do rendimento e da valorização das suas acções.

\section{4 - CONCLUSÃO}

Para efeitos de cálculo do resultado por acção, torna-se necessário distinguir empresas com estruturas de capital simples, que apresentarão um único resultado por acção, das empresas com estruturas de capital complexas que terão de divulgar, obrigatoriamente, dois tipos de resultados por acção: resultado por acção básico e resultado por acção diluído.

De acordo com a IAS n. ${ }^{\circ} 33$ e com o SFAS n. ${ }^{\circ} 128$, uma empresa tem uma estrutura de capital simples quando o seu capital é constituído apenas por acções ordinárias ou quando não tem quaisquer potenciais acções ordinárias, as quais poderão assumir a forma de opções ${ }^{27}$, warrants $^{28}$ ou outros direitos, que após convertidos ou exercidos poderão, no seu conjunto, diluir o resultado por acção. Consequentemente, uma empresa terá uma estrutura de capital complexa quando tiver potenciais acções ordinárias, que farão reduzir o resultado por acção caso venham a ser emitidas.

O grande problema com que nos deparámos e que, em grande medida, justifica a elaboração deste artigo foi o facto de apenas o ponto 3.11 da DC n. ${ }^{\circ} 20$ ser a única referência ao resultado por acção. Além do mais, a fórmula de cálculo constante na directriz corresponde à forma mais simples do resultado por acção, que serve somente às empresas que possuam uma estrutura de capital simples, pelo que se ignora o tratamento de quaisquer mecanismos potencialmente dilutivos.

Para além desta "omissão", também nos parece que o cálculo do resultado por acção deveria ter sido contextualizado e enquadrado à semelhança do que foi realizado na IAS $n .^{\circ} 33$. Bem sabemos que não se trata de uma directriz referente ao resultado por acção, mas uma vez que é a única a introduzir, contabilisticamente e de forma normativa e directa, o conceito de resultados por acção em Portugal, julgamos que a inclusão do cálculo e apresentação deste conceito foi tratada com demasiada ligeireza, pois trata-se de uma temática que pode revelar contornos muito complexos. 
É, também, verdade que por força da DC n. 18 as IAS são subsidiariamente aplicáveis em Portugal e, consequentemente, basta lançar mão da tradução para a língua portuguesa, efectuada pela Ordem dos Revisores Oficiais de Contas. Todavia, saliente-se que a tradução pura e simples da norma para português não retira problemas quanto à compreensão, interpretação e aplicação da norma em Portugal.

É, pois, neste contexto que nos propomos em futuros artigos desbravar mais algum terreno no que respeita à determinação, apresentação e divulgação dos resultados por acção básico e diluído, recorrendo, para tanto, ao preconizado pela IAS . $^{\circ} 33$ conjuntamente com o tratamento proposto pelo SFAS $n .^{\circ} 128$. 


\section{NOTAS}

${ }^{1}$ Nos termos do n. ${ }^{\circ}$, do artigo $1 .^{\circ}$ do Código dos Valores Mobiliários (CVM) são "valores mobiliários, além de outros que a lei como tal qualifique: $a$ ) as acções; $b$ ) as obrigações; $c$ ) os títulos de participação; $d$ ) as unidades de participação em instituições de investimento colectivo; $e$ ) os direitos à subscrição, à aquisição ou à alienação de valores mobiliários referidos nas alíneas anteriores, que tenham sido emitidos de modo autónomo; $f$ ) os direitos destacados dos valores mobiliários referidos nas alíneas anteriores $a$ ) a $d$ ), desde que o destaque abranja toda a emissão ou série ou esteja previsto no acto de emissão." São ainda equiparáveis a valores mobiliários "... outros documentos representativos de situações jurídicas homogéneas que visem, directa ou indirectamente, o financiamento de entidades públicas ou privadas e que sejam emitidos para distribuição junto do público, em circunstâncias que assegurem os interesses dos potenciais adquirentes." (cf. o disposto no $n .^{\circ} 2$ do artigo $1 .^{\circ}$ do CVM)

${ }^{2}$ As obrigações convertíveis conferem ao seu titular a possibilidade de as converter num número definido de acções da mesma empresa, em condições prédeterminadas, durante um determinado período.

${ }^{3}$ Os accionistas podem, por sua opção, trocar acções preferenciais por acções ordinárias a um rácio pré-determinado.

${ }^{4}$ Os warrants conferem ao seu detentor, normalmente mediante o pagamento de uma quantia inicial, o direito de adquirir um determinado montante de acções, a um preço fixado e durante um certo período de tempo.

${ }^{5}$ Emissão de acções ordinárias mediante o preenchimento de determinados requisitos, como sejam o alcançar de determinado nível de resultados ou volume de vendas.

${ }^{6}$ Valores mobiliários com potencial para serem exercidos ou convertidos e reduzirem o valor do resultado por acção da empresa.

${ }^{7}$ No seu parágrafo 6 , a IAS n. ${ }^{\circ} 33$ define acção ordinária como um instrumento de capital que está subordinado a todas as outras classes de instrumentos de capital. As acções ordinárias só participam no lucro líquido do período depois de qualquer outro tipo de acções, como por exemplo as acções preferenciais. Entende-se por instrumento de capital qualquer contrato que evidencie um interesse accionista numa determinada entidade, i.e., um interesse residual nos activos de uma entidade depois de deduzidos todos os seus passivos (cf. parágrafo 9 da IAS n. ${ }^{\circ} 33$ ).

${ }^{8}$ Uma potencial acção ordinária é um instrumento financeiro ou um qualquer outro contrato que possibilite ao seu titular vir a ser possuidor de acções ordinárias (cf. parágrafo 6 da IAS n. ${ }^{\circ} 33$ ). Entende-se por instrumento financeiro qualquer contrato que dê origem, simultaneamente, a um activo financeiro numa entidade e a um passivo financeiro ou a um instrumento de capital noutra entidade (cf. parágrafo 9 da IAS n. ${ }^{\circ} 33$ ).

${ }^{9}$ De acordo com o disposto no n. ${ }^{\circ} 1$, do artigo $198 .^{\circ}$ do CVM, "Considera-se mercado de valores mobiliários qualquer espaço ou organização em que se admite a negociação de valores mobiliários por um conjunto indeterminado de pessoas actuando por conta própria ou através de mandatário." Refira-se que as operações de mercado sobre valores mobiliários podem ter lugar no mercado primário ou no mercado secundário. $\mathrm{O}$ mercado primário compreende o conjunto dos mercados de valores mobiliários onde as entidades emitentes procedem à emissão dos títulos, ou seja, à sua colocação junto dos investidores. Este segmento compreende, portanto, 
as operações relativas à primeira transacção daqueles valores. Por seu turno, o mercado secundário engloba o conjunto dos mercados de valores mobiliários onde têm lugar todas as transacções posteriores à primeira (mercado primário), ou seja, para onde se encaminham todas as ordens de compra e de venda em momento posterior ao da sua colocação.

10 Resultado atribuído, no período, a cada acção ordinária em circulação durante o período de relato.

11 Resultado atribuído, no período, a cada acção ordinária depois de se ter tido em consideração o efeito de todas as potenciais acções ordinárias que estiveram em circulação durante o período e que têm um efeito de diluição.

${ }^{12} \mathrm{O}$ split de acções consiste no aumento proporcional do número de acções ordinárias em circulação, através da diminuição do seu valor nominal.

${ }^{13}$ Num reverse share split o emitente reduz o número de acções ordinárias em circulação através do aumento do seu valor nominal, mantendo, assim, inalterado o valor do Capital Próprio da empresa.

14 As acções preferenciais são uma categoria especial de acções designadas de preferenciais porque contêm determinadas características ou atributos que as acções ordinárias não possuem. Os atributos mais comuns que podem conter as acções preferenciais são os seguintes:

1. Acções preferenciais acumulativas - dividendos que não tenham sido pagos em anos anteriores, acumulam e serão pagos em anos posteriores antes que qualquer lucro seja distribuído aos accionistas ordinários. Se a Administração não declarar o dividendo das acções preferenciais acumulativas, este dividendo passa a constituir um dividendo em atraso, que não sendo uma dívida da empresa, uma vez que não existe nenhuma dívida enquanto a Administração não o declarar, não é registado como uma dívida mas é divulgado numa nota às Demonstrações Financeiras. As acções preferenciais não acumulativas raramente são emitidas, uma vez que um dividendo não declarado encontra-se perdido para sempre para o accionista preferencial e, como tal, este tipo de acções tem muito pouca aceitação.

2. Acções preferenciais participativas - os detentores de acções preferenciais participativas participam, proporcionalmente, com os accionistas ordinários em qualquer distribuição de lucros, para além da taxa a que têm direito. Ou seja, acções preferenciais participativas em $5 \%$, receberão não apenas $5 \%$ do par ou do valor inscrito no título, mas também dividendos às mesmas taxas daquelas que forem pagas aos accionistas ordinários, se esses montantes ultrapassarem os $5 \%$. Contudo, as acções preferenciais participativas nem sempre são completamente participativas, como acima descrito, mas parcialmente participativas. Por exemplo, poderá ser dito que acções preferenciais a $5 \%$ poderão participar até uma taxa máxima total de $10 \%$, a partir da qual cessa a sua participação em distribuições adicionais de lucros ou que acções preferenciais a 5\% apenas participarão em distribuições de lucros adicionais que excedam uma taxa de $9 \%$ dos dividendos atribuídos às acções ordinárias.

3. Aç̧ões preferenciais convertíveis - os accionistas podem, por sua opção, trocar acções preferenciais por acções ordinárias a um rácio pré-determinado. $\mathrm{O}$ detentor de acções preferenciais convertíveis pode, assim, optar por continuar a beneficiar de um direito preferencial sobre os dividendos, ou, em alternativa, converter-se num accionista ordinário.

4. Aç̧ões preferenciais remíveis - beneficiam de algum privilégio patrimonial na sua emissão mas ficam sujeitas a remissão em data fixa ou quando a Assembleia Geral o deliberar. A remissão das acções constitui um meio técnico para terminar 
o privilégio, sem prejuízo para o accionista preferencial, que recebe o dinheiro investido.

15 Total do balanço: 1.500 .000 euros; total das vendas líquidas e outros proveitos: 3.000 .000 euros; número de trabalhadores empregados em média durante o exercício: 50 .

16 De acordo com o parágrafo n. ${ }^{\circ} 49$ (a) da Estrutura Conceptual do IASC (Framework for the Preparation and Presentation of Financial Statements), activo é um recurso controlado pela empresa em resultado de acontecimentos passados e do qual se espera, que fluam para a empresa, benefícios económicos futuros.

17 Passivo é uma obrigação presente da empresa proveniente de acontecimentos passados, de cuja liquidação se espera que resulte um exfluxo de recursos da empresa, incorporando benefícios económicos futuros (cf. parágrafo n. ${ }^{\circ} 49$ (b) da Estrutura Conceptual do IASC).

${ }^{18}$ Capital Próprio é o interesse residual nos activos da empresa depois de deduzidos todos os seus passivos (cf. parágrafo $\mathrm{n}^{\circ} 49$ (c) da Estrutura Conceptual do IASC).

${ }^{19}$ Cf. parágrafo n. ${ }^{\circ} 70$ (a) da Estrutura Conceptual do IASC.

${ }^{20}$ Cf. parágrafo n. ${ }^{\circ} 70$ (b) da Estrutura Conceptual do IASC.

${ }^{21}$ Cf. parágrafo $n .{ }^{\circ} 75$ da Estrutura Conceptual do IASC.

${ }^{22}$ Cf. parágrafo n. ${ }^{\circ} 79$ da Estrutura Conceptual do IASC.

${ }^{23}$ Segundo Carlos B. Costa (1999) são de incluir nesta rubrica os juros de depósitos bancários e a recuperação de dívidas anteriormente consideradas incobráveis.

${ }^{24}$ De notar que, por exemplo, no caso dos descontos de pronto pagamento, alguns autores defendem a sua não inclusão nesta rubrica. Entendemos que se a obtenção de um desconto por antecipação do prazo de pagamento, em substância tem subjacente um esforço financeiro e, consequentemente, se trata de uma opção que acarreta custos de financiamento acrescidos, o proveito desse esforço deverá traduzir-se numa dedução ao custo líquido do financiamento, logo incluída neste conceito.

${ }^{25}$ Considera-se que a informação é materialmente relevante se a sua omissão ou inexactidão influenciarem as decisões económicas dos utentes, tomadas na base das Demonstrações Financeiras (cf. parágrafo n. ${ }^{\circ} 30$ do Framework for the Preparation and Presentation of Financial Statements).

${ }^{26}$ A problemática das operações em descontinuação encontra-se tratada com detalhe na IAS n. ${ }^{\circ} 35-$ Discontinuing Operations.

${ }^{27}$ A opção é um contrato que permite ao seu detentor, mediante o pagamento de uma quantia inicial (prémio), assegurar um preço máximo de compra ou mínimo de venda (preço de exercício) de um determinado montante de activos, sem perder o benefício de uma eventual evolução favorável das cotações de mercado do activo subjacente. Existem dois tipos de opções:

(1) Opção de compra (call option) - confere ao seu comprador o direito, mas não a obrigação, de comprar ao vendedor da opção um determinado montante de activos a um preço previamente fixado (preço de exercício), durante um determinado período de tempo;

(2) Opção de venda (put option) - confere ao seu comprador o direito, mas não a obrigação, de vender um montante determinado de activos a um preço pré determinado (preço de exercício) durante um dado período.

${ }^{28}$ Os warrants conferem ao seu detentor, normalmente mediante o pagamento de uma quantia inicial, o direito de adquirir um determinado montante de activos (por exemplo, acções), a um preço fixado e durante um certo período de tempo. O preço 
de compra oferecido nos warrants é, normalmente, superior ao valor de mercado do activo, em contraste com os direitos de subscrição, de novos activos, emitidos abaixo do valor de mercado. Os warrants diferem das opções de compra de acções na medida em que a sua subscrição é pública, sendo transaccionados livremente nos mercados secundários, ao passo que as opções de compra de acções são, normalmente, oferecidas apenas aos funcionários da empresa emitente (in Dictionary of Banking Terms, pág. 670). Em Portugal, os warrants só podem ser emitidos se as aç̧ões da empresa emitente se encontrarem cotadas em Bolsa de Valores. 


\section{REFERÊNCIAS BIBLIOGRÁFICAS}

ASSOCIAÇÃO DOS TÉCNICOS OFICIAIS DE CONTAS, (Ed.), (1999), Demonstrações Financeiras e IVA Intracomunitário, Acções de Formação, Lisboa;

DELANEY, Patrick R. et al. (1998), Interpretation and Application of Generally Accepted Accounting Principles (GAAP) 98, John Wiley \& Sons, Inc., New York;

EPSTEIN, Barry J. e MIRZA, Abbas Ali (1998), Interpretation and Application of International Accounting Standards (IAS) 98, John Wiley \& Sons, Inc., New York;

EPSTEIN, Barry J. e MIRZA, Abbas Ali (2000), Interpretation and Application of International Accounting Standards (IAS) 2000, John Wiley \& Sons, Inc., New York;

ERNST \& YOUNG LLP, (Ed.), (1997), Financial Reporting Developments: Earnings per Share - FASB Statement 128, s.l.;

FINANCIAL ACCOUNTING STANDARDS BOARD (1997), Statement of Financial Accounting Standards (SFAS) n. ${ }^{\circ} 128$ - Earnings per Share, Original Pronouncements, John Wiley \& Sons, Inc., New York;

FITCH, Thomas P. (1993), Dictionary of Banking Terms, $2^{\text {nd }}$ edition, Barron's, New York;

GONÇALVES DA SILVA, F. V. e PEREIRA, J. M. Esteves (1994), Contabilidade das Sociedades, Plátano Editora, Lisboa;

INTERNATIONAL ACCOUNTING STANDARDS COMMITTEE, (Ed.), (1989), Framework for the Preparation and Presentation of Financial Statements, Londres;

INTERNATIONAL ACCOUNTING STANDARDS COMMITTEE, (Ed.), (1997), International Accounting Standard (IAS) n..$^{\circ} 1$ - Presentation of Financial Statements, Londres;

INTERNATIONAL ACCOUNTING STANDARDS COMMITTEE, (Ed.), (1993), International Accounting Standard (IAS) n. 8 - Net Profit or Loss for the Period, Fundamental Errors and Changes in Accounting Policies, Londres;

INTERNATIONAL ACCOUNTING STANDARDS COMMITTEE, (Ed.), (1997), International Accounting Standard (IAS) n. ${ }^{\circ} 33$ - Earnings per Share, Londres;

INTERNATIONAL ACCOUNTING STANDARDS COMMITTEE, (Ed.), (2000), International Accounting Standards 2000, Londres;

KIESO, Donald E. e WEYGANDT, Jerry J. (1998), Intermediate Accounting, $9^{\text {th }}$ edition, John Wiley \& Sons, Inc., New York;

PORTUGAL, Ministério das Finanças, Decreto-Lei n. ${ }^{\circ} 44 / 99$, Estabelece a obrigatoriedade da adopção do sistema de inventário permanente e da elaboração da demonstração dos resultados por funções e define os 
elementos básicos da listagem do inventário fisico, de 12 de Fevereiro, Diário da República n. ${ }^{\circ}$ 36/99, I Série-A;

PORTUGAL, Ministério das Finanças, Decreto-Lei n. ${ }^{\circ}$ 486/99, Aprova $o$ novo Código dos Valores Mobiliários, de 13 de Novembro, Diário da República n. ${ }^{\circ} 265 / 99$, I Série-A;

PORTUGAL, Ministério das Finanças: Comissão de Normalização Contabilística, Directriz Contabilistica $n^{\circ} 18$ - Objectivos das demonstrações financeiras e principios contabilísticos geralmente aceites, de 5 de Agosto de 1997, Diário da República n. ${ }^{\circ} 179$, II Série;

PORTUGAL, Ministério das Finanças: Comissão de Normalização Contabilística, Directriz Contabilística $n^{\circ} 20$ - Demonstração dos resultados por funções, de 5 de Agosto de 1997, Diário da República n. ${ }^{\circ}$ 179, II Série; 